\title{
Proliferation inhibition and apoptosis induction of imatinib-resistant chronic myeloid leukemia cells via PPP2R5C down-regulation
}

\author{
Qi Shen ${ }^{1 \dagger}$, Sichu Liư ${ }^{1 \dagger}$, Yu Chen ${ }^{1,2}$, Lijian Yang ${ }^{1}$, Shaohua Chen ${ }^{1}$, Xiuli Wu' ${ }^{1}$ Bo Li ${ }^{1}$, Yuhong Lu ${ }^{3}$, Kanger Zhu ${ }^{3}$ \\ and Yangqiu Li ${ }^{1,2^{*}}$
}

\begin{abstract}
Despite the success of imatinib and other tyrosine kinase inhibitors (TKIs), chronic myeloid leukemia (CML) remains largely incurable, and a number of CML patients die due to Abl mutation-related drug resistance and blast crisis. The aim of this study was to evaluate proliferation inhibition and apoptosis induction by down-regulating PPP2R5C gene expression in the imatinib-sensitive and imatinib-resistant CML cell lines K562, K562R (imatinib resistant without an Abl gene mutation), 32D-Bcr-Abl WT (imatinib-sensitive murine CML cell line with a wild type Ab/ gene) and 32D-Bcr-Abl T315I (imatinib resistant with a T315I Ab/ gene mutation) and primary cells from CML patients by RNA interference. PPP2R5C siRNAs numbered 799 and 991 were obtained by chemosynthesis. Non-silencing siRNA scrambled control (SC)-treated, mock-transfected, and untreated cells were used as controls. The PPP2R5C mRNA and protein expression levels in treated CML cells were analyzed by quantitative real-time PCR and Western blotting, and in vitro cell proliferation was assayed with the cell counting kit-8 method. The morphology and percentage of apoptosis were revealed by Hoechst 33258 staining and flow cytometry (FCM). The results demonstrated that both siRNAs had the best silencing results after nucleofection in all four cell lines and primary cells. A reduction in PPP2R5C mRNA and protein levels was observed in the treated cells. The proliferation rate of the PPP2R5C-siRNA-treated CML cell lines was significantly decreased at $72 \mathrm{~h}$, and apoptosis was significantly increased. Significantly higher proliferation inhibition and apoptosis induction were found in K562R cells treated with PPP2R5C-siRNA799 than K562 cells. In conclusion, the suppression of PPP2R5C by RNA interference could inhibit proliferation and effectively induce apoptosis in CML cells that were either imatinib sensitive or resistant. Down-regulating PPP2R5C gene expression might be considered as a new therapeutic target strategy for CML, particularly for imatinib-resistant CML.
\end{abstract}

Keywords: CML, Imatinib resistant, PPP2R5C, RNA interference, Apoptosis, Cell proliferation

\section{Introduction}

Chronic myeloid leukemia (CML) is a hematopoietic stem cell disorder that occurs because of $\mathrm{t}(9 ; 22)$ (q34; q11) translocations. CML prognoses markedly improved after the introduction of Abl tyrosine kinase inhibitors (TKIs). Since its approval in 2001 for frontline CML management, imatinib has proven to be effective in achieving high remission rates and improving prognosis.

\footnotetext{
* Correspondence: yangqiuli@hotmail.com

${ }^{\dagger}$ Equal contributors

'Institute of Hematology, Jinan University, Guangzhou 510632, China

${ }^{2}$ Key Laboratory for Regenerative Medicine of Ministry of Education, Jinan

University, Guangzhou 510632, China

Full list of author information is available at the end of the article
}

However, up to $33 \%$ of patients will not achieve an optimal response. Most patients with CML treated with imatinib will relapse if treatment is withdrawn, and numerous CML patients die due to $A b l$ mutation-related drug resistance and blast crisis. These circumstances have led researchers to develop a new generation of TKIs. Although second-generation TKIs, such as AMN107, appear to improve the treatment of CML, TKI resistance and relapse also frequently occur in patients. de novo and secondary TKI resistance are significant problems for CML [1-5]. Therefore, how to treat patients with CML who are resistant to Bcr-Abl tyrosine kinase inhibitors is an important and urgent issue for clinical hematology.

\section{Ciomed Central}


Moreover, TKIs have significant off-target inhibitory effects on multiple kinases. TKIs, through the off-target PPP2R5Cinhibition of kinases important for B-cell signaling, reduce memory B-cell frequency and induce significant impairment of B-cell responses in CML [6]. TKIs also impair $\mathrm{T}$ cell function e.g., imatinib impairs CD8+ $\mathrm{T}$ cells specifically directed against leukemiaassociated antigen function [7].

Further advances in the treatment of CML may require the development of novel agents such as siRNAs that target specific CMLs or specific immunotherapies without significant toxicity that may have cooperative effects with TKIs $[8,9]$. siRNAs targeting the $B c r-A b l$ and multidrug-resistance $(M D R-1)$ genes were used in an anti-CML study and demonstrated that a breakpointspecific short-interfering RNA (siRNA) was capable of decreasing $\mathrm{Bcr}-\mathrm{Abl}$ protein expression and antagonizing Bcr-Abl-induced biochemical activities [10-12].

Synthetic small interfering RNAs (siRNAs) are promising gene-targeting agents that have shown great potential, particularly for development as specific anti-leukemia treatment $[13,14]$. A combination of $c$-raf and $b c l-2$ siRNAs induced apoptosis in HL-60, U937, and THP cell lines and increased chemosensitivity to etoposide and daunorubicin [15].

Recently, we were the first to show that a higher PPP2R5C expression level is found in peripheral blood mononuclear cells from chronic phase CML patients, and PPP2R5C expression is significantly decreased in patients who achieved CR [16]. PPP2R5C is a regulatory $B$ subunit of protein phosphatase $2 \mathrm{~A}$ (PP2A), which is one of the main serine-threonine phosphatases in mammalian cells, and it maintains cell homeostasis by counteracting most of the kinase-driven intracellular signaling pathways [17]. The PPP2R5C gene encodes five different spliced variants including

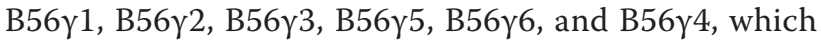
is only found in mice. The locus for the functional PPP2R5C gene is at $14 \mathrm{q} 32.2$, and a nonfunctional $B 56 \gamma 1$ pseudogene for $P P P 2 R 5 C$ is located at $3 \mathrm{p} 21.3$ [16-18]. PPP2R5C plays a crucial role in cell proliferation, differentiation, and transformation based on its induction of the dephosphorylation of p53 at various residues [19]. It has been reported that the dynamic nuclear distribution of the $B 56 \gamma 3$ regulatory subunit controls nuclear PP2A activity and may be responsible for the tumor-suppressive function of PP2A [18]. Recently, alterations in the PPP $2 R 5 C$ expression pattern that are associated with malignant transformation have been characterized in lung cancer, and the PPP2R5C mutation F395C disrupts the B56 $\gamma-\mathrm{p} 53$ interaction [20].

To confirm the role of PPP $2 R 5 C$ in the proliferation of $\mathrm{CML}$, we analyzed the effect of down-regulating PPP2R5C gene expression in imatinib-sensitive and imatinib-resistant chronic myeloid leukemia (CML) cell lines and primary cells from CML patients by RNA interference and confirmed the proliferation inhibition and apoptosis induction of PPP2R5C in CML cells.

\section{Methods \\ Cell culture}

Imatinib-sensitive K562 cells (Institutes for Biological Sciences Cell Resource Center, Chinese Academy of Sciences, Shanghai, China) carrying 210 kDa wild-type Bcr-Abl were grown in Roswell Park Memorial Institute (RPMI) 1640 medium (Gibco-BRL, Grand Island, NY, USA) with 10\% fetal calf serum (FCS) (Sijiqing Co., Hangzhou, China) and maintained in a humidified incubator at $37^{\circ} \mathrm{C}$ and $5 \%$ $\mathrm{CO}_{2}$. Imatinib-resistant $\mathrm{K} 562 \mathrm{R}$ cells (provided by Prof. Jingxuan Pan, Department of Pathophysiology, Zhongshan School of Medicine, Sun Yat-sen University, Guangzhou, China) carrying $210 \mathrm{kDa}$ wild-type Bcr-Abl were routinely maintained in the same medium including $1 \mu \mathrm{M}$ imatinib. 32D-Bcr-Abl WT, an imatinib-sensitive murine CML cell line carrying a wild type $\mathrm{Abl}$ gene, and 32D-Bcr-Abl T315I, an imatinib-resistant CML cell line carrying a T315I mutation in Bcr-Abl (provided by Prof. Lin Qiu, Harbin Institute of Hematolgy \& Oncology, Harbin, China), were established and maintained in RPMI 1640 medium with $10 \%$ FCS as previously described [21]. In addition, PBMCs from two patients with newly diagnosed, untreated chronic phase CML (case 1: female, 18 years old, PB white blood cell number (WBC): $108.6 \times 10^{9} / \mathrm{L}, \mathrm{PB}$ blast + promyelocyts $10 \%$, case 2 : female, 30 years old, WBC: $208.53 \times 10^{9} / \mathrm{L}$, PB blast + promyelocytes $3 \%$ ), which were obtained with consent (the procedures were conducted according to the guidelines of the Medical Ethics committee of the health bureau of Guangdong Province of China), were grown in RPMI 1640 with 15\% FCS. All experiments were performed using cells in the exponential growth phase.

\section{siRNA design and synthesis}

The siRNAs PPP2R5C-siRNA799 (Chinese patent number: ZL 201110340411.1) and PPP2R5C-siRNA991 (Chinese patent number: ZL 201110337837.1), which target domains in the sixth and between the eighth and ninth exons in the PPP2R5C gene (ACCESSION NM_178587), respectively, and a non-silencing siRNA scrambled control (SC) were designed with online software (http://www.invitrogen.com) and synthesized by Invitrogen (Carlsbad, CA, USA) [22]. An Alexa Red Oligo (Invitrogen) was used to measure transfection efficiency.

\section{Nucleofection}

Cells were collected by centrifugation and resuspended at $2.5 \times 10^{6}$ cells $/ 100 \mu \mathrm{l}$ for the CML cell lines and primary CML cells in the appropriate Nucleofector ${ }^{\mathrm{rm}}$ kit $\mathrm{V}$ solution (Amaxa Biosystems, Cologne, Germany) [23-26]. 
Malignant CML cells were nucleofected with $3 \mu \mathrm{g}$ of the PPP2R5C siRNAs or a non-silencing scrambled control (SC) siRNA using the T-003 program of the Nucleofection Device II (Amaxa Biosystems). Mock-transfected cells nucleofected without siRNA were used as a negative control. After nucleofection, the cells were immediately mixed with $500 \mu \mathrm{l}$ of pre-warmed culture medium and transferred into culture plates. The treated cells were incubated at $37^{\circ} \mathrm{C}$ for 3 days for cell proliferation, apoptosis and microarray analyses. Three independent experiments for the cell lines were performed every $24 \mathrm{~h}$.

\section{RNA isolation, reverse transcription, real-time qRT-PCR}

Total RNA was isolated from different samples (CML cell lines and primary CML cells) using TRIzol (Invitrogen). cDNA for qRT-PCR was synthesized using the Superscript II RNaseH Reverse Transcriptase Kit (Invitrogen). The expression level of PPP $2 R 5 C$ and the $\beta 2-M G$ reference gene was determined by SYBR Green I real-time PCR. PCR was performed as previously described [16]. The sequences of the primers used in qRT-PCR are as follows: PPP2R5C: 5'-GTAATAAAGCGGGCAGCAG G-3' (forward) and 5'-CAAAGTCAAAGAGGACGCA ACA-3' (reverse) and $\beta_{2} M: 5^{\prime}$-CAGCAAGGAC TGGT CTTTCTAT-3' (forward) and 5'-GCGGCATCTTCAA ACCTC-3' (reverse) [22].

\section{Immunoblotting}

A total of $2 \times 10^{6} \mathrm{~K} 562$ and K562R cells were collected 72 $\mathrm{h}$ after nucleofection, and proteins were extracted using a RIPA total protein lysate kit (Shennengbocai, Shanghai, China). Protein quantification was performed according to conventional methods. Protein samples $(30 \mu \mathrm{g})$ were added to SDS loading buffer, heated at $100^{\circ} \mathrm{C}$ for $5 \mathrm{~min}$, and then electrophoresed in 10\% SDS-polyacrylamide gels at $100 \mathrm{~V}$ for $30 \mathrm{~min}$ followed by $120 \mathrm{~V}$ for $50 \mathrm{~min}$ (Bio$\mathrm{Rad})$. The separated proteins were transferred onto nitrocellulose membranes (Invitrogen) using a tank system (Bio-Rad). The membranes were blocked with 3\% blocking reagent for $2 \mathrm{~h}$ and then incubated with polyclonal rabbit anti-human PPP2R5C antibody (1:200; Sigma, USA) or mouse anti-actin antibody (1:1000; Lianke, Hangzhou, China) followed by incubation with goat anti-rabbit or donkey anti-mouse IgG antibodies, respectively (Jackson ImmunoResarch, USA; Lianke, Hangzhou, China). Immunoreactive proteins were visualized by chemiluminescence (Lianke, Hangzhou, China), and images were obtained with a Vilber Lourmat system (UVI, UK). The expression level of PPP2R5C was calculated with image quantitation analysis software using $\beta$-actin as a reference gene [25,26].

\section{Cell proliferation assays}

The proliferation of CML cell lines and primary CML cells was indirectly assayed using the CCK-8 kit (Dojindo,
Japan), which stains living cells. After transfection, approximately $5 \times 10^{4}$ cells in $100 \mu \mathrm{L}$, including control cells, were incubated in triplicate in 96-well plates. At 24,48 , and $72 \mathrm{~h}$, the CCK-8 reagent $(10 \mu \mathrm{L})$ was added to each well, and the cells were incubated at $37^{\circ} \mathrm{C}$ for $6 \mathrm{~h}$. The optical density at $450 \mathrm{~nm}$ was measured using an automatic microplate reader (Synergy4; Bio-Tek, Winooski, VT, USA) [23].

\section{Apoptosis analysis}

At $72 \mathrm{~h}$ post-transfection, $5 \times 10^{4}$ of the CML cell lines and primary CML cells were fixed, washed twice with PBS, and stained with Hoechst 33258 staining solution according to the manufacturer's instructions (Beyotime, Haimen, China). Changes in the nuclei of cells after Hoechst 33258 staining were observed with a confocal laser-scanning microscope (LSM 510 META DuoScan; Carl Zeiss, Germany). The cell lines $\left(5 \times 10^{5}\right)$ were collected 48 and $72 \mathrm{~h}$ after transfection and then prepared with FITC-labeled anti-Annexin-V (BD Pharmingen, San Diego, CA, USA) and propidium iodide (Kaiji, Nanjing, China) according to the manufacturers' protocol and measured by flow cytometry (Beckman Coulter, Fullerton, CA, USA). The results were analyzed using Windows MDI 2.9 software [23].

\section{Statistical analysis}

Statistical analyses were performed with paired $t$-tests and one-way ANOVA using SPSS 11.5 statistical software. Kruskal-Wallis analysis was used to analyze the PPP2R5C mRNA levels in different samples. Differences were considered statistically significant at $p<0.05$.

\section{Results}

\section{PPP2R5C-specific siRNAs suppress PPP2R5C expression in} CML cells

We first verified transfection efficiency with Alexa Red Oligo-transfected K562, K562R, 32D-Bcr-Abl WT and 32D-Bcr-Abl T315I cell lines, which was $86.38 \pm 6.82 \%$ (Figure 1), $40.52 \pm 4.48 \%$ (Figure 2), $50.97 \pm 4.36 \%$ (Additional file 1: Figure S1) and $63.26 \pm 3.75 \%$ (Additional file 2: Figure S2), respectively, and Alexa Red Oligotransfected primary CML cells, which was only $15.6 \%$.

To determine the suppression of PPP2R5C expression in CML cells after siRNA treatment, PPP2R5C mRNA expression was analyzed by qRT-PCR 24,48 , and $72 \mathrm{~h}$ after nucleofection, while the suppression of PPP2R5C protein expression in K562 and K562R cells was analyzed by immunoblotting $72 \mathrm{~h}$ after nucleofection. PPP2R5CsiRNA799 and PPP2R5C-siRNA991 were measured from 24 to $72 \mathrm{~h}$ post-transfection. The PPP2R5C mRNA level in K562 cells was $7.00 \pm 0.83$ and $6.44 \pm 0.87 \%$ at $24 \mathrm{~h}$ with PPP2R5C-siRNA799 and PPP2R5C-siRNA991 transfection, respectively, while the SC level was $26.11 \pm 2.69 \%$ 

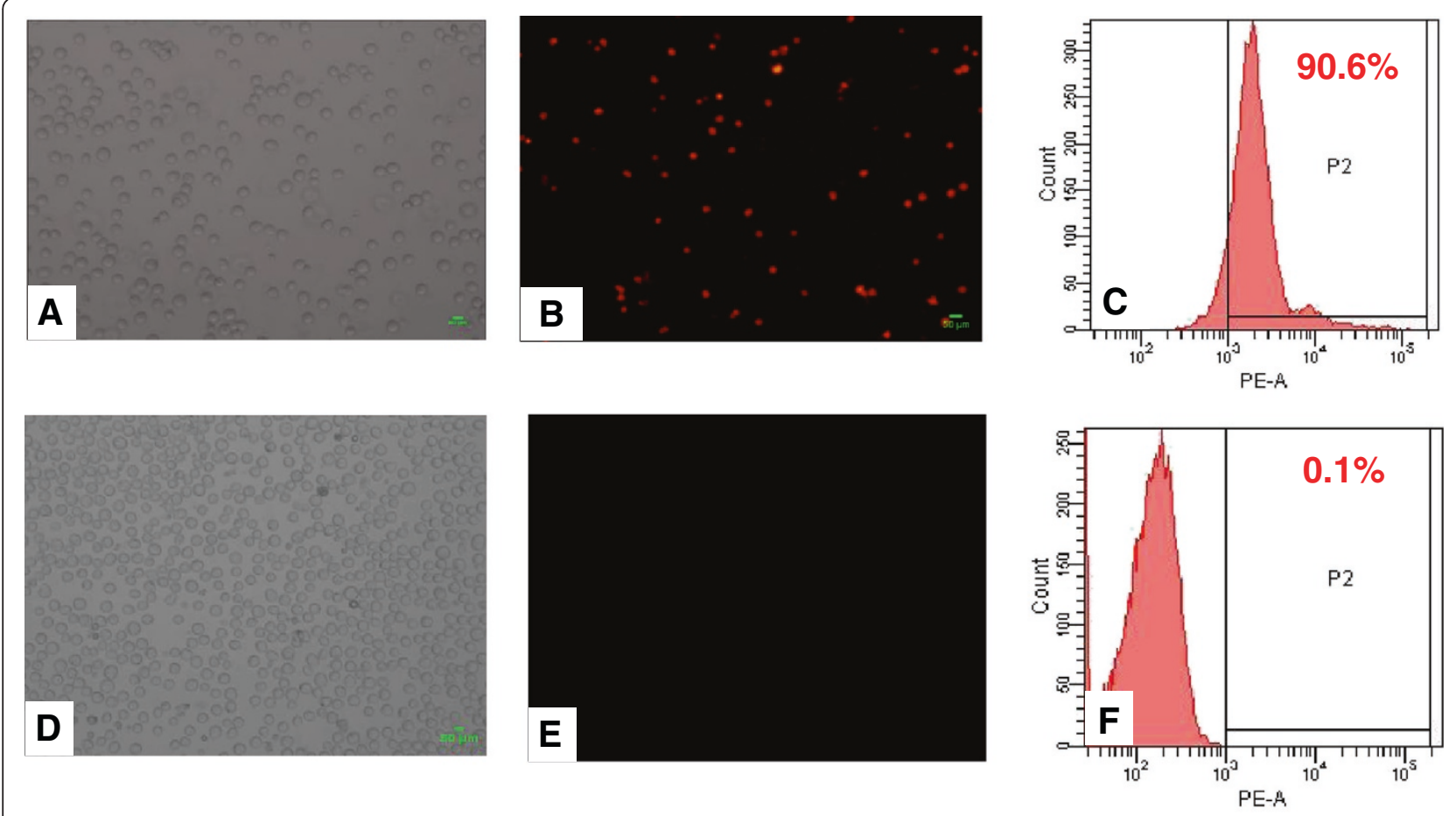

G

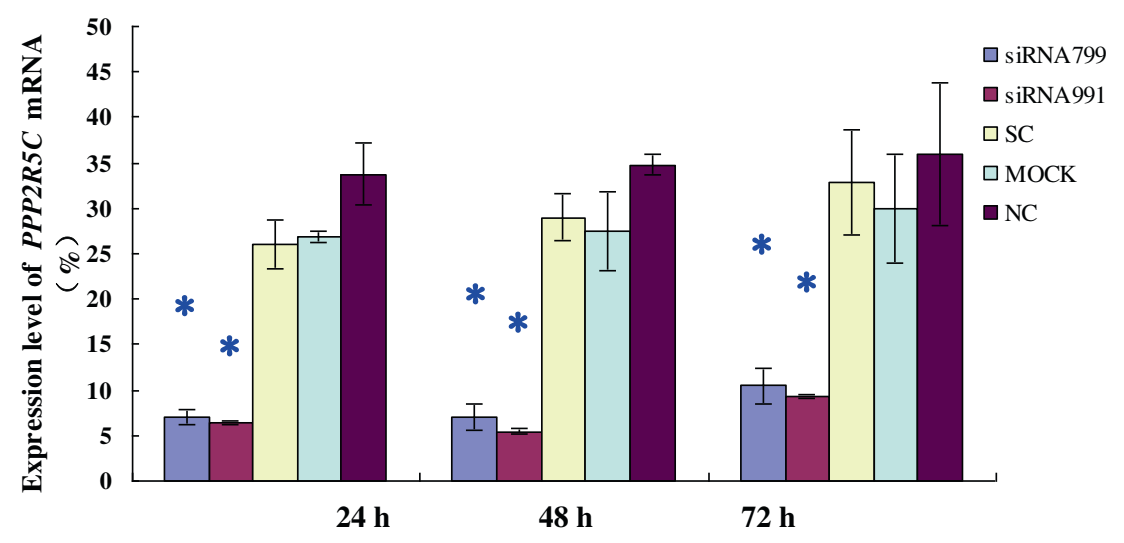

H

PPP2R5C

$\beta$-actin

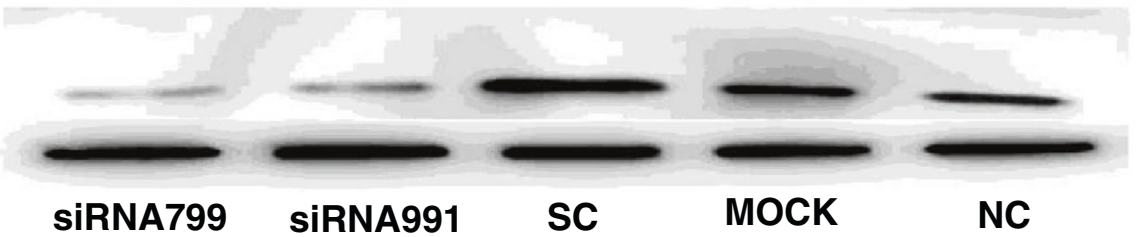

Figure 1 Inhibition of PPP2R5C expression in K562 cells by RNA interference. Detection of the transfection efficiencies in K562 cells by fluorescence microscopy $(\mathrm{Bar}=50 \mu \mathrm{m})$ and flow cytometry (Positive cells are shown as the P2 domain). A and B: Alexa Red Oligo-transfected K562 cells (fluorescence microscope); C: Alexa Red Oligo-transfected K562 cells (FCM); D and E: Mock-transfected K562 cells (fluorescence microscope); $\mathbf{F}$ : Mock-transfected K562 cells (FCM). G: Suppression of PPP2R5C mRNA expression as measured by qRT-PCR after nucleofection with PPP2R5C siRNAs $(3 \mu \mathrm{g}) .{ }^{*}, p<0.05$ compared with expression in cells treated with non-silencing control RNA. $\mathbf{H}$ : PPP2R5C protein level in K562 cells $72 \mathrm{~h}$ after nucleofection with PPP2R5C siRNAs $(3 \mu \mathrm{g})$. Non-treated cells ( $\mathrm{nc}$ ), mock-transfected (mock), and scrambled control non-silencing RNA (SC)-treated cells were used as controls. 

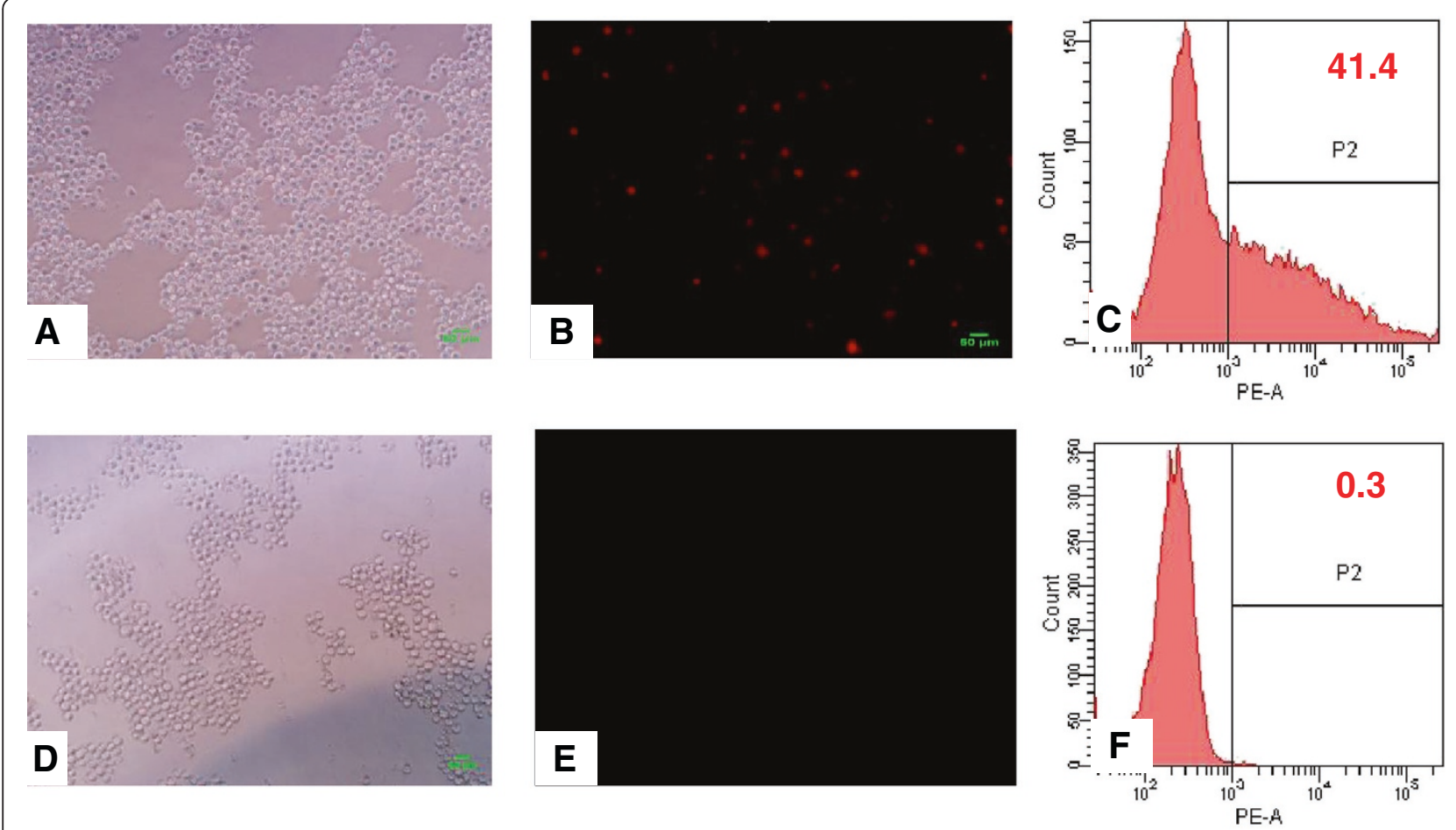

G

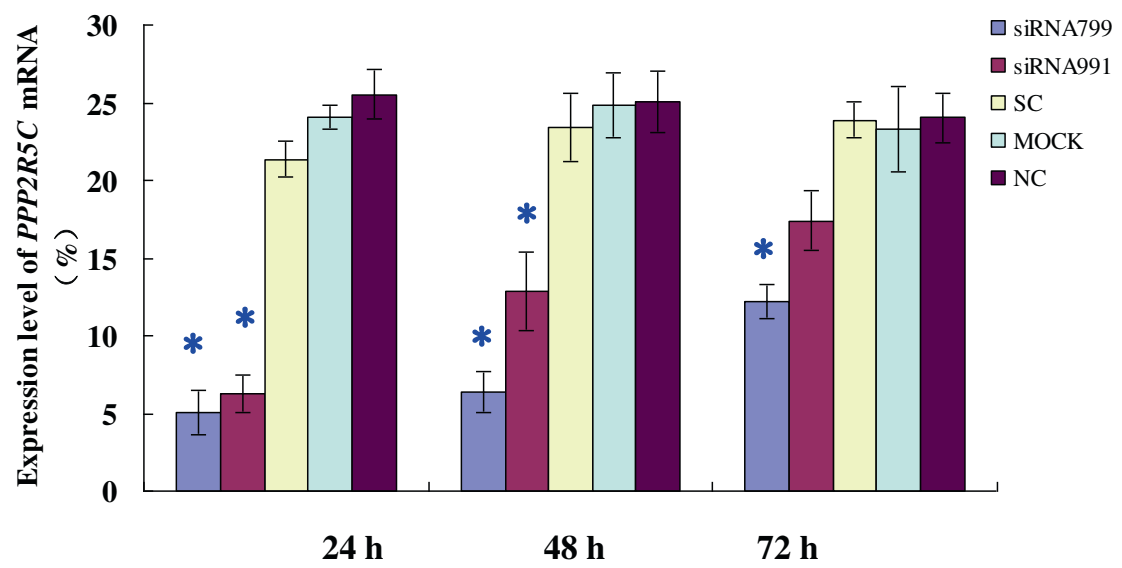

H

PPP2R5C

$\beta$-actin

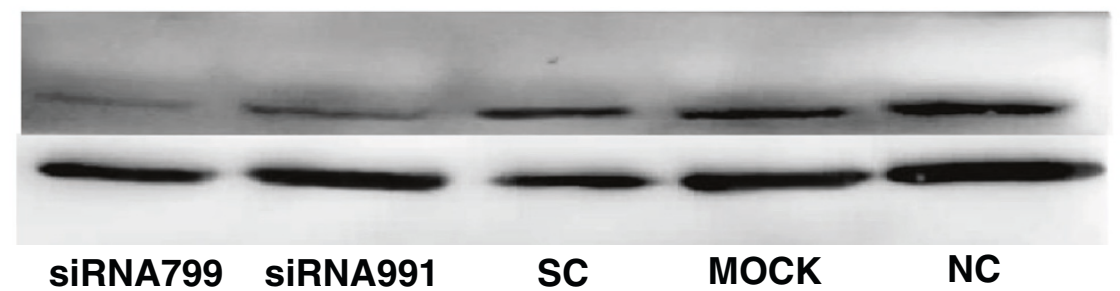

Figure 2 Inhibition of PPP2R5C expression in K562R cells by RNA interference. Detection of the transfection efficiencies in K562R cells by fluorescence microscopy $(\mathrm{Bar}=50 \mu \mathrm{m})$ and flow cytometry (positive cells are shown in the P2 domain). $\mathbf{A}$ and $\mathbf{B}$ : Alexa Red Oligo-transfected K562R cells (fluorescence microscope); C: Alexa Red Oligo-transfected K562R cells (FCM); D and E: Mock-transfected K562R cells (fluorescence microscope); F: Mock-transfected K562R cells (FCM). G: Suppression of PPP2R5C mRNA expression as measured by qRT-PCR after nucleofection with PPP2R5C siRNAs $(3 \mu \mathrm{g}) . *, p<0.05$ compared with expression in cells treated with control non-silencing RNA. H: PPP2R5C protein level in K562R cells $72 \mathrm{~h}$ after nucleofection with PPP2R5C siRNAs $(3 \mu \mathrm{g})$. Non-treated cells $(\mathrm{nc})$, mock-transfected (mock), and scrambled non-silencing control RNA (SC)-treated cells were used as controls. 


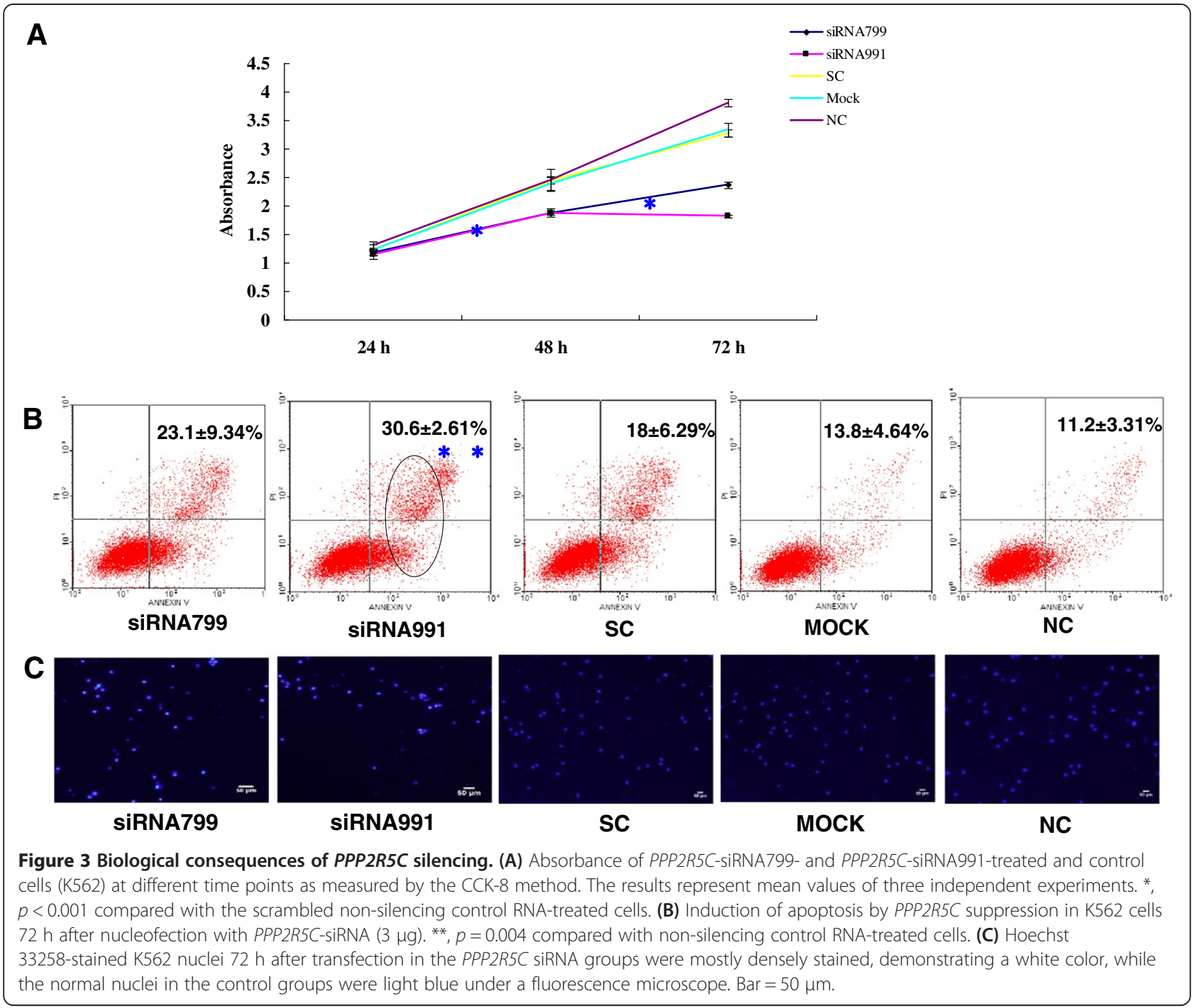

(Figure1). The PPP2R5C mRNA level in K562R cells was $5.06 \pm 1.47$ and $6.23 \pm 1.19 \%$ at $24 \mathrm{~h}$ with $P P P 2 R 5 C$ siRNA799 and PPP2R5C-siRNA991 transfection, respectively, while the SC level was $21.37 \pm 1.17 \%$ (Figure 2 ). Similar inhibition results were found for the protein levels. The PPP2R5C protein expression level was reduced by 55.26 and $52.58 \%$ in PPP2R5C-siRNA799- and PPP2R5C-siRNA991-treated K562 cells, respectively, compared with the control level at $72 \mathrm{~h}$ (Figure 1), while the reduction in treated $\mathrm{K} 562 \mathrm{R}$ cells was 53.81 and $50.21 \%$, respectively (Figure 2).

We also analyzed the suppression effect of both siRNAs in the murine CML cell lines 32D-Bcr-Abl WT and 32D-Bcr-Abl T315I. The PPP2R5C mRNA level in 32D-Bcr-Abl WT cells was $5.71 \pm 2.45$ and $8.88 \pm 1.39 \%$ at $24 \mathrm{~h}$ with PPP2R5C-siRNA799 and PPP2R5C-siRNA991, respectively, while the SC level was $20.25 \pm$ $1.37 \%$ (Additional file 1: Figure S1). The PPP $2 R 5 C$ mRNA level in 32D-Bcr-Abl T315I cells was 3.14 \pm 2.04 and $3.18 \pm 1.13 \%$ at $24 \mathrm{~h}$ with $P P P 2 R 5 C$-siRNA799 and PPP2R5C-siRNA991, respectively, while the SC level was $12.04 \pm 1.11 \%$ (Additional file 2: Figure S2). A reduction in the PPP2R5C mRNA levels was also observed at 48$72 \mathrm{~h}$. The PPP2R5C mRNA level in primary leukemic CML cells was decreased 4.71 and $6.09 \%$ at $24 \mathrm{~h}$ with PPP2R5C-siRNA799 and PPP2R5C-siRNA991, respectively, compared with the SC (14.01\%). A reduction in the PPP2R5C mRNA level was also observed at 48-72 $\mathrm{h}$ (Additional file 3: Figure S3). Although the 32D-Bcr-Abl WT and 32D-Bcr-Abl T315I cells are originally from a mouse, the PPP2R5C siRNAs target the same sequences in these cells due to homology of the mouse PPP2R5C and that of humans according to data from GenBank.

PPP2R5C suppression inhibits proliferation and induces apoptosis in CML cells

The proliferation rate of $\mathrm{K} 562$ and K562R cells transfected with PPP2R5C-siRNA799 and PPP2R5C-siRNA991 was 


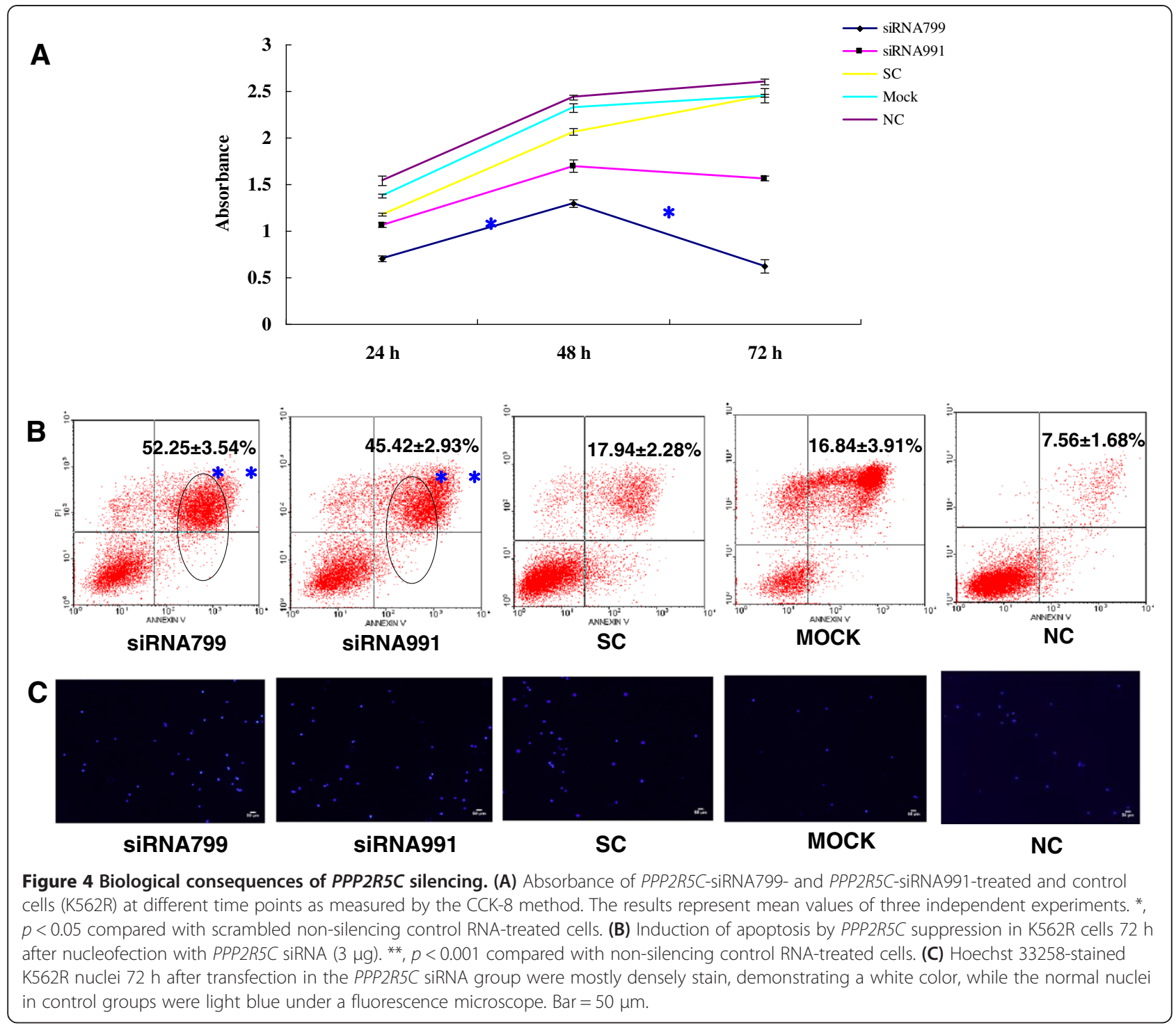

significantly decreased at 48-72 h compared with controls $(p<0.0001)$ (Figures 3 and 4$)$. The proliferation rate of 32D-Bcr-Abl WT with PPP2R5C-siRNA799 was significantly decreased at 48-72 h, and it was significantly decreased at $72 \mathrm{~h}$ with PPP2R5C-siRNA991 $(p<0.0001)$ (Figure 5). The proliferation rate of the 32D-Bcr-Abl T315I cells with PPP2R5C-991-siRNA was significantly decreased at 48-72 h compared with controls $(p<0.0001)$ (Figure 5). The proliferation rate of primary CML cells with PPP2R5C-siRNA799 and PPP2R5C-siRNA991 was significantly decreased at $72 \mathrm{~h}(p<0.0001)$ (Figure 6). K562 cells transfected with PPP2R5C-799-siRNA showed a significant increase in Annexin V/PI-positive cells (apoptosis) at $72 \mathrm{~h}$, reaching $30.6 \pm 2.61 \%(p=0.04)$ (Figure 3 ). Moreover, the apoptotic (Annexin V/PI-positive cells) rate of K562R cells transfected with PPP2R5C-799-siRNA and PPP2R5C-991-siRNA showed a significant increase at
$72 \mathrm{~h}$, reaching $52.25 \pm 3.54$ and $45.42 \pm 2.93 \%$, respectively $(p<0.0001)$ (Figure 4). Similar results were found for 32D-Bcr-Abl WT and 32D-Bcr-Abl T315I cells transfected with PPP2R5C-siRNA799 and PPP2R5C-siRNA991. The apoptotic rate of $32 \mathrm{D}$-Bcr-Abl WT cells was significantly increased at $72 \mathrm{~h}$, reaching $55.25 \pm 3.22$ and $58.08 \pm 2.91 \%$ with PPP2R5C-siRNA799 and PPP2R5C-siRNA991, respectively $(p<0.0001)$ (Figure 5$)$, while it reached $38.86 \pm$ 3.75 (PPP2R5C-siRNA799) and 46.04 $\pm 2.82 \%$ (PPP2R5CsiRNA991) in 32D-Bcr-Abl T315I cells treated for $72 \mathrm{~h}$ ( $p=0.005, p=0.001$ ) (Figure 5). Furthermore, morphological changes consistent with apoptosis were observed by Hoechst staining (Figures 3 and 4).

We next compared the effect of the PPP2R5C siRNAs on imatinib-sensitive and imatinib-resistant cell lines, and interestingly, significantly higher proliferation inhibition and apoptosis induction were found for K562R cells treated 

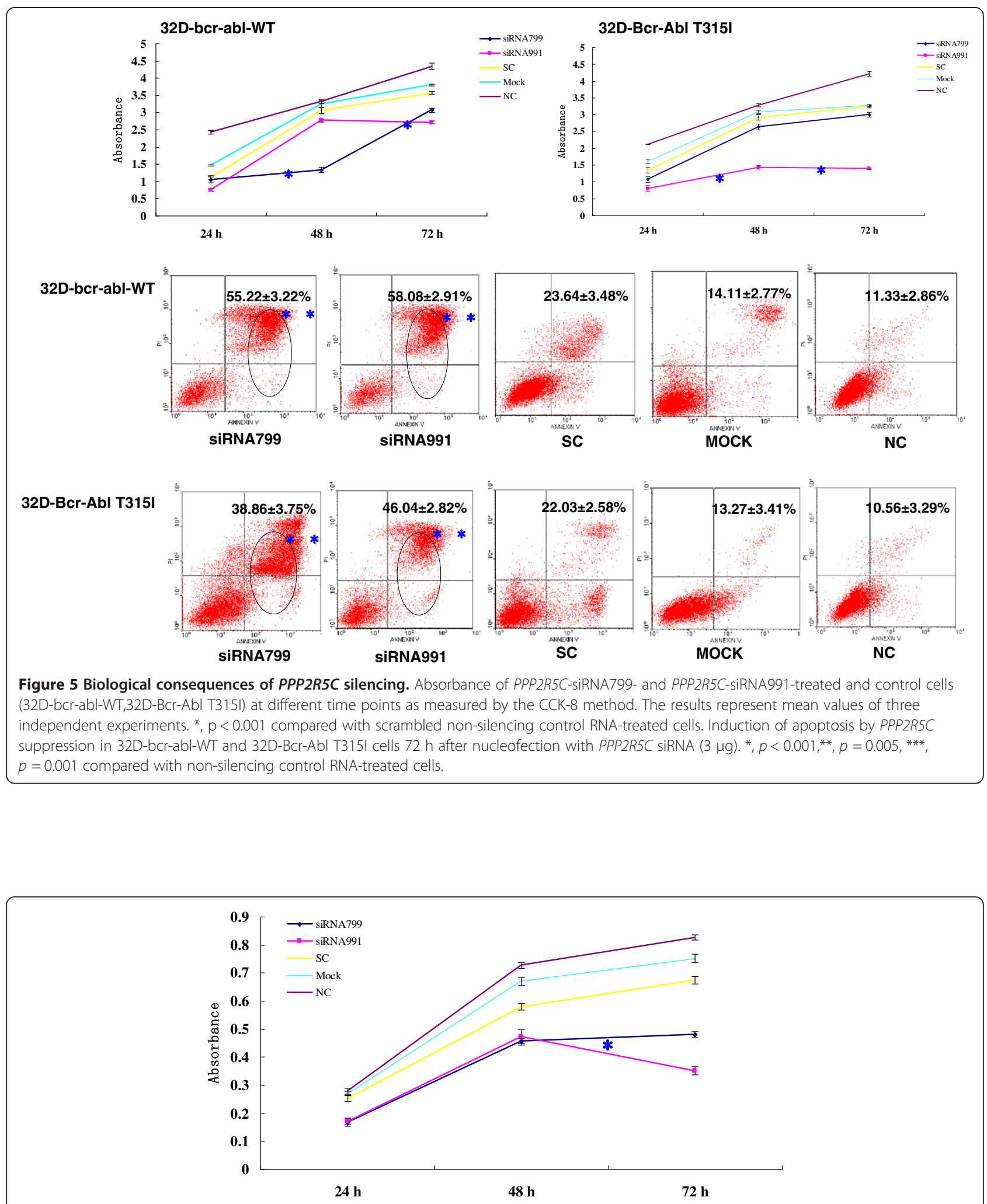

Figure 6 Absorbance of PPP2R5C-siRNA799 and PPP2R5C-siRNA991-treated primary CML and control cells at different time points as measured by the CCK-8 method. The results represent the mean values of three independent experiments. ${ }^{*},<0.001$ compared with non-silencing scrambled control RNA-treated cells. 

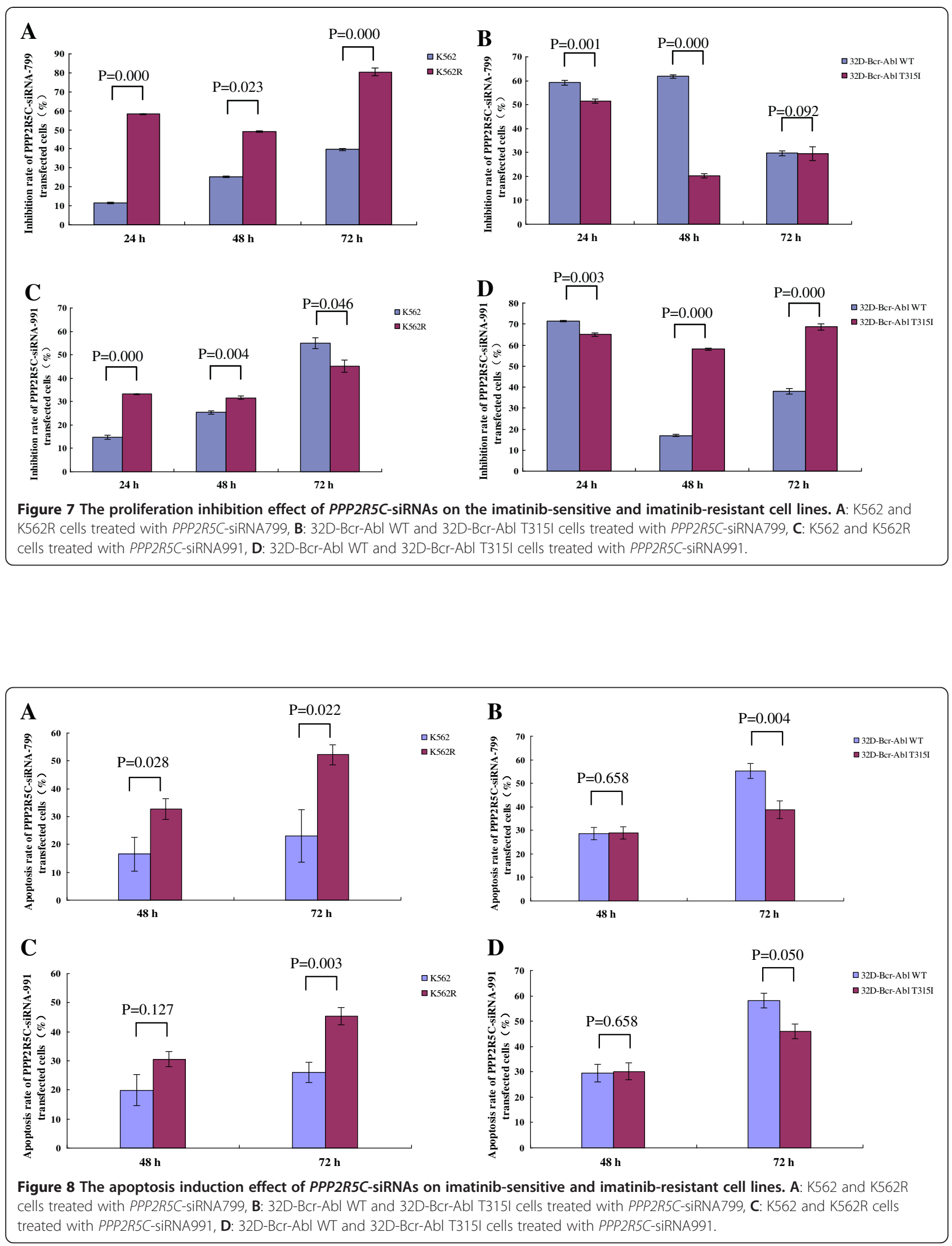
with PPP2R5C-siRNA799 than for K562 cells (Figures 7 and 8 ). In contrast, the inhibition of proliferation and apoptosis was higher for 32D-Bcr-Abl WT than 32D-Bcr-Abl T315I cells treated with the same siRNA (Figures 7 and 8). However, the effect of PPP2R5C-siRNA991 on the inhibition of proliferation and apoptosis induction appeared variable between the imatinib sensitive and resistant cells (Figures 7 and 8).

\section{Discussion}

Targeted therapies are directed at unique molecular signatures of cancer cells to produce greater efficacy with less toxicity. The development and use of such therapeutics allow us to practice personalized medicine and improve cancer care [27]. Imatinib is the first successful molecular drug specifically targeting the $A b l$ gene and has proven to be effective in achieving high remission rates and improving CML prognosis. Because TKI resistance and relapse frequently occur in patients, new targeted drugs that can specifically inhibit TKI-resistant CML urgently need to be developed. RNAi represents a new alternative for CML treatment that overcomes the difficulties of current drug treatments such as acquired resistance. The therapeutic targeting of $B c r-A b l$ transcripts by siRNA was demonstrated in imatinib-resistant CML cells $[10,28]$.

PPP2R5C plays a crucial role in cell proliferation, differentiation, and transformation based on its induction of the dephosphorylation of p53 at various residues [19] and may be responsible for the tumor-suppressive function of PP2A [18]. To confirm the role of PPP2R5C down-regulation on the inhibition of CML cells, particularly TKI-resistant CML cells, we used two PPP2R5C siRNAs that target different exon sequences to analyze their effect on the inhibition of proliferation and apoptosis induction in CML cells. Moreover, to investigate the PPP2R5C siRNA effects in imatinib-resistant CML cells, we selected two pairs of CML cell lines, including the imatinib-sensitive cell lines $\mathrm{K} 562$ and 32D-Bcr-Abl WT and the imatinib-resistant cell lines K565R, which lacks an $A b l$ mutation, and 32D-Bcr-Abl T315I, which has an T315I $A b l$ mutation, to compare the different changes induced by PPP2R5C siRNA.

In general, RNAi effects are detected between 24 and 72 $\mathrm{h}$ after siRNA transfection. We demonstrated that the siRNAs effectively silenced $P P P 2 R 5 C$ post-transcriptionally, and the control siRNA had no obvious influence $72 \mathrm{~h}$ after nucleofection. These results were confirmed at the RNA and protein levels. siRNAs targeting different exon domains had different efficacies for PPP2R5C gene silencing and subsequent biological consequences. Both PPP2R5C siRNAs demonstrated significant effects on the knockdown of PPP2R5C expression in CML cell lines, and PPP2R5C-siRNA799, which targets exon six, demonstrated robust knockdown of PPP2R5C expression in K562R cells at all time points.

There are reports that siRNAs targeting $B c r-a b l$ increased sensitivity to imatinib in Bcr-Abl-overexpressing cells and cells expressing the imatinib-resistant Bcr-Abl kinase domain mutations H396P and Y253F [10,28]. There are no reports regarding the effects of the suppression of PPP $2 R 5 C$ on changing cell biological functions. Our previous study first demonstrated that the suppression of PPP $2 R 5 C$ by RNAi effectively inhibited the proliferation of the Molt-4 and Jurkat cell lines; however, the suppression of PPP2R5C by RNAi could not significantly induce apoptosis in Molt-4 and Jurkat $\mathrm{T}$ cells [22]. In contrast, the PPP2R5C siRNAs not only inhibited cell proliferation but also induced apoptosis in imatinib-sensitive and imatinib-resistant CML cell lines. These results indicated that down-regulating PPP2R5C could significantly inhibit the proliferation of CML cells, and the underlying mechanism might be different between CML and T-ALL cells. More importantly, we found a significantly higher inhibition effect in K562R cells treated with PPP2R5C-siRNA799, and the inhibition effect in 32D-Bcr-Abl T315I cells, which have a T315I Abl mutation, was similar to that of 32D-BcrAbl WT cells. Such effects are particularly important for the targeted therapy of imatinib-resistant CML cells that either lack an $A b l$ mutation and have primary and imatinib-induced resistance or those with an $A b l$ T315I mutation, which resist new-generation TKIs. Therefore, it is interesting to analyze the molecular mechanism of PPP2R5C siRNA-mediated cell proliferation suppression in different leukemia cells. It has been reported that TKI-resistant, Philadelphia chromosome-positive cell lines without an $A b l$ mutation are unique because they dephosphorylate ERK1/2 and STAT5 after imatinib treatment, while $\mathrm{PI} 3 \mathrm{~K} / \mathrm{AKT} 1 / \mathrm{mTOR}$ activity remains unaffected. The inhibition of AKT1 leads to apoptosis in imatinib-resistant cell lines. Therefore, these $\mathrm{Ph}+$ cell lines show a form of imatinib-resistance attributable to the constitutive activation of the PI3K/AKT1 pathway [3]. Whether down-regulating PPP2R5C contributes similar effects to the inhibition of PI3K/AKT1/mTOR signaling requires further investigation. We also found that PPP2R5C siRNA could inhibit the proliferation of primary CML cells in limited experiments, and this effect should be further explored using a larger patient cohort.

Moreover, whether PPP2R5C siRNAs could potentiate the efficacy of TKIs in imatinib-resistant cells is worthy of further investigation. One study has shown a synergistic effect between AMN107 and arsenic trioxide (ATO) or $B c r-A b l$-siRNA in the $\mathrm{K} 562 \mathrm{R}$ imatinib-resistant cells or those with an $\mathrm{H} 396 \mathrm{P}$ abl mutation, indicating that the combination of AMN107 and ATO or siRNA may 
represent a new strategy for the treatment of imatinibresistant CML patients [10,29].

In conclusion, our findings provide evidence for the effect of proliferation inhibition and apoptosis induction in CML cells by PPP2R5C knockdown, and such effects may particularly benefit developing a strategy including a combination of targeted therapy using TKIs for resistant cells. A successful clinical trial demonstrated that the in vivo application of targeted nonvirally delivered synthetic $B c r-a b l$ siRNA in a female patient with recurrent CML that was imatinib resistant (Y253F mutation) and chemotherapy after an allogeneic hematopoietic stem cell transplantation could silence the expression of the $B c r-A b l$ gene [28]. These data imply that siRNA may be suitable for development as a specific anti-leukemia treatment. However, a recent study demonstrated that the phosphatase activity of PP2A is suppressed in chronic myeloid leukemia and other malignancies characterized by aberrant oncogenic kinase activity, and preclinical studies show that the pharmacological restoration of PP2A tumor-suppressor activity by PP2Aactivating drugs (e.g., FTY720) effectively antagonizes cancer development and progression [30]. These findings appear to be contrary to our results, and further characterization of the function of the different regulatory B subunits of PP2A and a discussion of the different effects on the different PP2A target subunits is needed.

\section{Additional files}

Additional file 1: Figure $\mathbf{S 1}$. Inhibition of PPP $2 R 5 C$ expression in 32D-bcr-abl-WT cells by RNA interference. Alexa Red Oligo-transfected (A) and mock-transfected (B) 32D-bcr-abl-WT cells (B) $11 \mathrm{~h}$ after transfection as measured with FCM (Positive cells are shown as the P2 domain). (C) Suppression of PPP2R5C mRNA expression as measured by qRT-PCR after nucleofection with PPP2R5C siRNAs $(3 \mu \mathrm{g})$ compared with expression in cells treated with non-silencing control RNA.

Additional file 2: Figure S2. Inhibition of PPP2R5C expression in 32D-Bcr-Abl T315I cells by RNA interference. Alexa Red Oligo-transfected (A) and mock-transfected (B) 32D-Bcr-Abl T315l cells $11 \mathrm{~h}$ after transfection as measured with FCM (positive cells are shown in the P2 domain). (C) Suppression of PPP2R5C mRNA expression as measured by qRT-PCR after nucleofection with PPP2R5C siRNAs $(3 \mu \mathrm{g})$ compared with expression in cells treated with non-silencing control RNA.

Additional file 3: Figure S3. Inhibition of PPP2R5C expression in primary CML cells by RNA interference. A: CML cells from a case with chronic phase CML treated with Alexa Red Oligo $11 \mathrm{~h}$ after transfection as measured by FCM (positive cells are shown in the P2 domain) with mock-transfected primary CML cells used as control (B). (C) Suppression of PPP2R5C mRNA expression as measured by qRT-PCR after nucleofection with PPP2R5C siRNAs $(3 \mu \mathrm{g})$ compared with expression in cells treated with non-silencing control RNA.

\section{Competing interests}

The authors declare that they have no competing interests.

\section{Authors' contributions}

YQL contributed to concept development and study design. QS performed the nucleofection, real-time PCR, cell proliferation assays and apoptosis analysis, SCL performed the immunoblotting and apoptosis analysis, YC screened the highly efficient and specific PPP2R5C siRNAs, and LJY, SHC, XLW and $\mathrm{BL}$ helped to collect samples and perform cell culture. YHL and KEZ was responsible for the collection of clinical data. YQL and QS coordinated the study and helped draft the manuscript. All authors read and approved the final manuscript.

\section{Acknowledgements}

This study was supported by grants from National Natural Science Foundation of China (30871091), a collaborate grant for HK-Macao-TW of the Ministry of Science and Technology (2012DFH30060), the Guangdong Science \& Technology Project (2012B050600023), Science and Technology Innovation Key Project of Guangdong Higher Education Institutes (kjcxzd1013) and Key Discipline Construction Foundation of Jinan University.

\section{Author details}

'Institute of Hematology, Jinan University, Guangzhou 510632, China. ${ }^{2}$ Key Laboratory for Regenerative Medicine of Ministry of Education, Jinan University, Guangzhou 510632, China. ${ }^{3}$ Department of Hematology, the First Affiliated Hospital of Jinan University, Guangzhou 510632, China.

Received: 17 August 2013 Accepted: 31 August 2013

Published: 3 September 2013

\section{References}

1. Jabbour E, Cortes J, Kantarjian H: Treatment selection after imatinib resistance in chronic myeloid leukemia. Target Oncol 2009, 4:3-10.

2. Okabe S, Tauchi T, Tanaka Y, Ohyashiki K: Dasatinib preferentially induces apoptosis by inhibiting Lyn kinase in nilotinib-resistant chronic myeloid leukemia cell line. J Hematol Oncol 2011, 4:32.

3. Quentmeier H, Eberth S, Romani J, Zaborski M, Drexler HG: BCR-ABL1independent PI3Kinase activation causing imatinib-resistance. $J$ Hematol Oncol 2011, 4:6.

4. Bhamidipati PK, Kantarjian H, Cortes J, Cornelison AM, Jabbour E Management of imatinib-resistant patients with chronic myeloid leukemia. Ther Adv Hematol 2013, 4:103-117.

5. Ross DM, Branford S, Seymour JF, Schwarer AP, Arthur C, Yeung DT, Dang P, Goyne JM, Slader C, Filshie RJ, Mills AK, Melo JV, White DL, Grigg AP, Hughes TP: Safety and efficacy of imatinib cessation for CML patients with stable undetectable minimal residual disease: results from the TWISTER study. Blood 2013, 122:515-522.

6. de Lavallade H, Khoder A, Hart M, Sarvaria A, Sekine T, Alsuliman A, Mielke S, Bazeos A, Stringaris K, Ali S, Milojkovic D, Foroni L, Chaidos A, Cooper N, Gabriel I, Apperley J, Belsey S, Flanagan RJ, Goldman J, Shpall EJ, Kelleher P, Marin D, Rezvani K: Tyrosine kinase inhibitors impair B-cell immune responses in CML through off-target inhibition of kinases important for cell signaling. Blood 2013, 122:227-238.

7. Chen J, Schmitt A, Chen B, Rojewski M, Ringhoffer M, von Harsdorf S, Greiner J, Guillaume P, Döhner H, Bunjes D, Schmitt M: Imatinib impairs CD8+ T lymphocytes specifically directed against the leukemiaassociated antigen RHAMM/CD168 in vitro. Cancer Immunol Immunother 2007, 56:849-861.

8. Valencia-Serna J, Gul-Uludağ H, Mahdipoor P, Jiang X, Uludağ H: Investigating siRNA delivery to chronic myeloid leukemia K562 cells with lipophilic polymers for therapeutic BCR-ABL down-regulation. J Control Release 2013. doi:10.1016/j.jconrel.2013.05.014 [Epub ahead of print].

9. Li Y, Lin C, Schmidt CA: New insights into antigen specific immunotherapy for chronic myeloid leukemia. Cancer Cell Int 2012, 12:52.

10. Wohlbold L, van der Kuip H, Miething C, Vornlocher HP, Knabbe C, Duyster J, Aulitzky WE: Inhibition of bcr-abl gene expression by small interfering RNA sensitizes for imatinib mesylate (STI571). Blood 2003, 102:2236-2239.

11. Withey JM, Marley SB, Kaeda J, Harvey AJ, Crompton MR, Gordon MY: Targeting primary human leukaemia cells with RNA interference: Bcr-Abl targeting inhibits myeloid progenitor self-renewal in chronic myeloid leukaemia cells. Br J Haematol 2005, 129:377-380.

12. Rumpold H, Wolf AM, Gruenewald K, Gastl G, Gunsilius E, Wolf D: RNAimediated knockdown of P-glycoprotein using a transposon-based vector system durably restores imatinib sensitivity in imatinib-resistant CML cell lines. Exp Hematol 2005, 33:767-775.

13. Devi RS: siRNA-based approaches in cancer therapy. Cancer Gene Ther 2006, 13:819-829. 
14. Whitehead KA, Langer R, Anderson DG: Knocking down barriers: Advances in siRNA delivery. Nat Rev Drug Discov 2009, 8:129-138.

15. Cioca DP, Aoki Y, Kijosawa K: RNA interference is a functional pathway with therapeutic potential in human myeloid leukemia cell lines. Cancer Gene Ther 2003, 10:125-133.

16. Zheng $H$, Chen Y, Chen S, Niu Y, Yang L, Li B, Lu Y, Geng S, Du X, Li Y: Expression and distribution of the PPP2R5C gene in leukemia. $J$ Hematol Oncol 2011, 4:21.

17. Muneer S, Ramalingam V, Wyatt R, Schultz RA, Minna JD, Kamibayashi C: Genomic organization and mapping of the gene encoding the PP2A B56gamma regulatory subunit. Genomics 2002, 79:344-348.

18. Lee TY, Lai TY, Lin SC, Wu CW, Ni IF, Yang YS, Hung LY, Law BK, Chiang CW: The B56gamma3 regulatory subunit of protein phosphatase $2 A(P P 2 A)$ regulates $S$ phase-specific nuclear accumulation of PP2A and the $G 1$ to S transition. J Biol Chem 2010, 285:21567-21580.

19. Shouse GP, Cai X, Liu X: Serine 15 phosphorylation of p53 directs its interaction with B56gamma and the tumor suppressor activity of B56gamma-specific protein phosphatase 2A. Mol Cell Biol 2008, 28:448-456.

20. Shouse GP, Nobumori Y, Liu X: A B56gamma mutation in lung cancer disrupts the $\mathrm{p} 53$-dependent tumor-suppressor function of protein phosphatase 2A. Oncogene 2010, 29:3933-3941.

21. Qiu L, Wang XD, Yu BH, Ge F, Wang XL, Chen LJ, Han BH, Zhan ZM, Zhang $\mathrm{BL}, \mathrm{Ma}$ J: [Effect of a novel tyrosine kinase inhibitor HHGV678 on growth inhibition of Bcr-Abl wild type and IM-resistant cell lines in vitro]. Zhongguo Shi Yan Xue Ye Xue Za Zhi 2008, 16:1039-1043.

22. Chen Y, Liu S, Shen Q, Zha X, Zheng H, Yang L, Chen S, Wu X, Li B, Li Y: Differential gene expression profiles of PPP2R5C-siRNA-treated malignant T cells. DNA Cell Biol 2013. doi:10.1089/dna.2013.2138. Aug 13. [Epub ahead of print].

23. Huang X, Chen S, Shen Q, Chen S, Yang L, Grabarczyk P, Przybylski GK Schmidt CA, Li Y: Down regulation of BCL11B expression inhibits proliferation and induces apoptosis in malignant T cells by BCL11B-935siRNA. Hematology 2011, 6:236-242

24. Huang X, Shen Q, Chen S, Chen S, Yang L, Weng J, Du X, Grabarczyk P, Przybylski GK, Schmidt CA, Li Y: Gene expression profiles in BCL11B-siRNA treated malignant T cells. J Hematol Oncol 2011, 4:23.

25. Chen S, Huang X, Chen SH, Yang L, Shen Q, Zheng H, Li B, Grabarczyk P, Przybylski GK, Schmidt CA, Li Y: The role of $B C L 11 B$ in regulating the proliferation of human naïve T cells. Hum Immunol 2012, 73:456-464

26. Zha X, Chen S, Yang L, Shi L, Li B, Wu X, Lu Y, Li Y: Up-regulated TCRZ enhances interleukin-2 production in T-cells from patients with CML. DNA Cell Biol 2012, 31:1628-1635.

27. Yuan $Y$, Liao YM, Hsueh $C T$, Mirshahidi HR: Novel targeted therapeutics: inhibitors of MDM2, ALK and PARP. J Hematol Oncol 2011, 4:16.

28. Koldehoff $M$, Elmaagacli AH: Therapeutic targeting of gene expression by siRNAs directed against BCR-ABL transcripts in a patient with imatinib-resistant chronic myeloid leukemia. Methods Mol Biol 2009, 487:451-466.

29. Xia $Y$, Fang $H$, Zhang J, Du Y: Endoplasmic reticulum stress-mediated apoptosis in imatinib-resistant leukemic K562-r cells triggered by AMN107 combined with arsenic trioxide. Exp Biol Med (Maywood) 2013. [Epub ahead of print].

30. Perrotti D, Neviani P: Protein phosphatase $2 A$ : a target for anticancer therapy. Lancet Oncol 2013, 14:e229-e238.

doi:10.1186/1756-8722-6-64

Cite this article as: Shen et al:: Proliferation inhibition and apoptosis induction of imatinib-resistant chronic myeloid leukemia cells via PPP2R5C down-regulation. Journal of Hematology \& Oncology 2013 6:64.

\section{Submit your next manuscript to BioMed Central and take full advantage of:}

- Convenient online submission

- Thorough peer review

- No space constraints or color figure charges

- Immediate publication on acceptance

- Inclusion in PubMed, CAS, Scopus and Google Scholar

- Research which is freely available for redistribution

Submit your manuscript at www.biomedcentral.com/submit
C Biomed Central 